\title{
OTRO ASPECTO DEL TRAFICO COLONIAL CON LA PROVINCIA DE CUYO
}

\author{
por Sergio SepUlveda G.
}

Comunicación de Geografía Histórica presentada a la xxiii Semana de Geografia, celebrada en Mendoza y San Rafael (Rep. Argentina), entre el 6 y el 13 de marzo de 1961 .

\section{PREAMBULO}

No sin cierta aprehensión hemos elegido este tema con el sentimiento del que imprudentemente entra en un dominio que no le pertenece por entero. Al respecto, creemos que es a los especialistas de esta tierra a quienes corresponde en plenitud de derecho el estudio de los grandes e insospechados tópicos que plantea esta realidad geografica. No obstante, los geógrafos chilenos que trabajamos la Geografía Histórica debemos reconocer que constantemente sentimos la tentación de encarar ciertos aspectos aún intocados de la geografía de Cuyo. Para justificar esta actitud y librarnos de parecer pretenciosos tenemos una razón valedera, la de poseer en nuestros archivos un rico patrimonio de documentos que cubren la mayor parte de la existencia colonial de Cuyo.

El presente trabajo explota esta coyuntura favorable, pretende asociarse así más activamente al aspecto conmemorativo que reviste esta reunión geográfica* y a la vez anhela dar testimonio de la importancia que se está asignando en mi país a los estudios de Geografía Histórica.

\section{Naturaleza de la vinculación con Cuyo}

De no querer insistir en sus aspectos geográficos sería inoficioso llamar de nuevo la atención aquí, acerca de los estrechos lazos que existieron en el pasado colonial entre el Reino de Chile y la Provincia de Cuyo. La antigua relación surge

- La xxirr Semana de la Geografía Argentina fue programada como acto oficial de la celebra. ción del Cuarto Centenario de la fundación de la ciudad de Mendoza. 
y se explica no sólo por la simple y relativa vecindad geográfica, sino que se fortalece andando el tiempo en virtud de una dependencia política y administrativa que rige asombrosamente por más de dos siglos, aunque en ese lapso ignora de manera aberrante las barreras naturales (1). En verdad, siempre aparecerá como un hecho extraordinario el carácter más o menos permanente de las comunicaciones efectivas, funcionando a pesar de la distancia de rispido temperamento que significaba el formidable obstáculo de la Cordillera Nevada. En este sentido, la invernación obligada en una $\mathbf{u}$ otra banda de las órdenes oficiales, de la correspondencia, de los viajeros y del comercio no fue por mucho tiempo un motivo suficientemente poderoso como para frustrar la vieja decisión administrativa o apresurar el divorcio de las dos economías.

Los incentivos del tráfico no faltan a lo largo de los años coloniales y las corrientes que engendran, animan con enorme preferencia los pasos y rutas del Norte de la región mediterránea chilena; pasos como los de los Patos, Uspallata y Piuquenes tienen todos un interés especial porque aproximan el mar chileno al transpaís cuyano y porque sirven al enriquecimiento de los mayores centros poblados de Santiago y Valparafso. Ninguno, sin embargo, tiene la gravitación del camino de Uspallata que constituye incuestionablemente el gran nexo colonial con la Provincia de Cuyo; por esta vía llegan a Santiago las mitas de Huarpes en el siglo xvir, cuya fuerza de trabajo era contratada por sus propios encomenderos en el medio santiaguino; por ahí pasan muchas de las partidas de ganado con que la Provincia transandina concurría a aliviar una de las necesidades planteadas por la guerra de Arauco; en fin, Uspallata es la ruta normal de los viajeros, de los correos y particularmente del grueso del comercio. Por Uspallata es que Mendoza y San Juan reciben una buena parte de los efectos de lujo llegados a Valparaíso por el lado del Pacífico (v. gr., las piezas de bramante y seda de Europa, los zapatos cordobanes, los sombreros de paja limeños, la loza inglesa, etc.) y los productos tropicales que consumen como el azúcar, el arroz y el aceite. Viceversa, por este camino y a lomo de mula conducen los arrieros hacia Chile los zurrones de yerba, los mazos de tabaco, los costales de pasas y las cabezas de ganado que demanda el Reino (2). Todavía más, Uspallata o Portillo era la ruta corriente de los esclavos negros, los cuales desembarcados en Buenos Aires seguian hacia Chile para encontrar a veces su destino final en Lima, si la suerte no los habia acompañado para huirse en la travesía de la Cordillera. Todo esto hace la importancia del camino de Uspallata y por eso es que las autoridades constantemente se preocupan de mantenerlo en buen estado, así es como aún hoy día se conservan muy cerca de las cumbres nevadas algunas de las casuchas que un Goberna-

(1) Nosotros preferimos usar esta terminologia antes que la de frontera natural y esto porque hoy dia sabemos que una montaña alta o un relieve accidentado, en muchos casos han sido fronteras menos insalvables que las representadas por regiones relativamente planas, pero sin condiciones de habitabilidad.

(2) Este es el tipo frecuente de mercaderia transportada scgún los libros de las Aduanas de la Cordillera que hemos consultado en los Archivos de la Contaduria Mayor. 
dor mandara construir para dar garantías al tráfico en la época más avanzada y tormentosa del año.

De todos modos ni Uspallata, ni los demás pasos nombrados resumen exclusivamente y en su totalidad Ias peripecias de la vinculación colonial con Cuyo.

\section{El tráfico por el Sur del Chile mediterráneo (34 a 37 lat. S.).}

En oposición con lo que es válido para el Norte de la región central no se tiene el mismo detallado conocimiento de los contactos habidos con Cuyo por la parte meridional de la región. Como no hay duda que estos contactos existieron, aunque en un plano mucho más modesto, hemos creido conveniente dar a conocer una documentación que permita desprender la singularidad del movimiento transcordillerano por el Sur. Los documentos forman parte de la correspondencia oficial y datan de fines del siglo xvin (1786-1800), su interés estriba entonces en que reflejan la situación existente en los años inmediatos al término del dominio de la Capitanía General sobre los territorios de allende los Andes.

Las varias comunicaciones intercambiadas entre el Comandante de la Frontera de Mendoza, José Fco. de Amigorena y los Gobernadores del Reino, Benavides, O'Higgins y Rézabal y de éstos con los subdelegados de Colchagua, Curicó y Maule, dan cuenta en años sucesivos de la presencia de españoles y chilenos en territorio cuyano, ingresados por los pasos del Sur. Los que entran persiguen fines de lucro y dan vida a un tránsito y a un comercio legalmente prohibidos. A despecho de esta condición este comercio adopta modalidades diversas.

\section{EL TRÁFICO Y SUS MóVILES.}

Los motivos o estímulos que inducen a los hombres del centro-sur a trasmontar la cordillera son variados, pero muchas veces algunos de ellos se usan como simples pretextos para disimular el objetivo verdadero que es el comercio ilícito de vinos y licores con los naturales del otro lado. Esta es la razón inequívoca por la cual el Comandante de la Frontera de Mendoza desconfía de una tropa de nueve chilenos que en 1786 le piden licencia para pasar la invernada, alegando que habian venido a llevar sal por el camino del Planchón y que a su regreso habian hallado cerrado el paso a causa de una gran nevada.

Lo cierto e innegable es que las necesidades de sal del Reino de Chile eran en aquel entonces bastante reales; el aprovisionamiento dependía del Perú en gran parte y particularmente el producto hacía falta en los territorios situados hacia la periferia de la Frontera Araucana, puesto que las últimas salinas de la costa central quedaban más al norte en el sector lagunar y medanoso que se extiende entre el curso inferior del Nilahue y las lagunas de Boyecura y. Vichuquén (ver mapa No 1). Por lo demás estas salinas fueron siempre de magnitud modesta, y lógicamente toda su producción era absorbida por las provincias septentrionales de la región. En consecuencia, las salinas de transcordillera interesaban vivamente al abastecimiento chileno, de ahí que existiera un comercio autorizado 
por licencia para traerla y lo propio ocurría con otros productos también necesarios, todo lo cual se deduce de una carta respuesta que dirige el Gobernador Arnbrosio de Benavides, en junio de 1786, a la autoridad de Mendoza en relación con el tráfico clandestino:

"por esta parte se han expedido repetidamente órdenes mías y de $m$ is antecesores, prohibiendo la internación a tierras de indios a los naturales del pais y aun cuando se permite a sujetos conocidos hasta las salinas y cordilleras extraer también yeso y brea es con la obligación de obtener formal pasaporte de las justicias" (\$).

El problema del aprovisionamiento de la sal seguía siendo apremiante años después, así lo deja suponer el acuerdo fuera de Parlamento (4), celebrado en la Villa de los Angeles el 9 de marzo de 1793 entre el Presidente O'Higgins y los caciques Pehuenches. En virtud de lo concertado españoles y pehuenches se comprometían para realizar una o dos expediciones por año a las salinas de la otra banda:

"juntando antes todos en un punto el mayor número de mulas y bestias de carga y que precisamente no habian de bajar de cuatro mil a ejemplo de lo que se practicaba en Buenos Aires, Córdoba, Mendoza y demás ciudades de aquel Virreinato, de donde anualmente salen en grandes caravanas los españoles e indios amigos a surtirse de un efecto tan necesario y cuya provisión por este medio ahorraría a la Provincia un gasto considerable de dinero que paga al Perú por la que de allí envía, pudiendo surtirse con tan poco costo y con la ventaja de mejorar de calidad en este efecto, sacándole abundantemente todos de las salinas, en donde en el día de hoy la extraen los mismos Pehuenches en pequeñas cantidades por su falta de "abios" para estas empresas y por la celeridad con que se ven obligados a hacer la provision por temor de los Huilliches" (5).

Pero hay todavía otros rubros aparte de la sal, el yeso y la brea que interesan a los comerciantes y les permiten justificar su tráfico con ventas vedadas, sabemos por ejemplo que también pasaban la Cordillera en busca del alquitrán, cuya fuente de aprovisionamiento estaba al parecer cerca de Malargue, lo que se in-

(3) Archivos de la Capitania Genera1. Vol. 507. "Sobre prohibir la entrada de españoles con ventas de vinos y otros fínes perniciosos a las tolderfas de Pehuenches por los boquetes de la Cordillera con motivo de algunas quexas de las Reducciones y del Comandante de la Frontera de Mendoza".

(4) Alude al Parlamento de Negrete, celebrado el 4 de marzo de 1793, en el campo de Negrete, entre el río Bío-Blo y el río Duqueco.

(5) Archivos de la Capitanía General. Vol. 507. 
fiere de un informe de José de Amigorena al Gobernador de Chile en 1796, que revela además la verdadera naturaleza del tráfico de venida:

“aviso a V. M. como una tropa de Arria del Capitán Vergara ha pasado a sacar alquitrán, el dueño de ella vino a este Malalgue a hacerse presente, actualmente está en dicho alquitrán. Traslado a V. S. esta noticia para que se sirva averiguar con que permiso y facultades se internan los troperos de esa banda a extraña jurisdicción a extraer sal, brea y alquitrán inhabilitando por este medio a los indios con el cambio de licores que les conducen para sacarles los mejores caballos y mulas como se ha visto en varias ocasiones" (6).

Las migraciones estacionales de ganado, inherentes al ambiente mediterráneo, son a su vez motivo de incursión y contacto con el ámbito transandino, a pesar de que dichas introducciones estaban también formalmente prohibidas. Es por esta causal precisamente que Don Ambrosio O'Higgins recrimina en 1792 al Subdelegado de Maule, después de haber escuchado en Santiago los reclamos del cacique pehuenche Guayquiman que ha expuesto por principal negocio fuerte queja contra la libertad de muchos españoles de esa jurisdicción que introducen sus ganados y animales a las tierras de ellos.

Atestación parecida, pero indicadora de la continuidad con que pasa el ganado y con él los individuos que entran en tratos con los indios, aparece en una carta del Comandante de la Frontera de Mendoza al Gobernador interino Rézabal en 1796 , en ella se dice textualmente:

"Tengo dado parte en varias ocasiones a ese superior Gobierno de que muchos sujetos de las Fronteras de Maule y Penco se trasladan a ésta con el pretexto de estar cuidando en los potreros de esta banda las haciendas de campo, alegando habérseles cerrado la Cordillera y se vienen a invernar en las tolderias de estos pehuenches, abandonando la ley cristiana que profesan y aun en este invierno me han traído aquí unos siete de los caciques que se quedaron conchavados, de que se sigue que no tienen tales encargos de haciendas y que acaso serían algunos malévolos que por sus delitos propios andan de ése para este Reino (7).

A raíz de la denuncia anterior el Subdelegado de Curicó hizo publicar un bando en el cual se ve con claridad la relación existente entre las veranadas de ganado y la internación ilícita de ventas, puesto que prohibe a los españoles introducir engordas de animales y a su sombra comercio de licores a tierras de indios pehuenches en las cordilleras inmediatas a dicho partido.

(6) Archivos de la Capitania General. Vol. 507.

(7) Archivos de la Capitanía General. Vol. 507. 
Resulta pues evidente que el verdadero atractivo de la corriente por el Sur es el comercio clandestino de vinos y licores y el transporte del ganado que otras veces se roba a los propios indios del otro lado. La mayor importancia del intercambio de vinos se explica simplemente porque en el oasis mendocino recién comenzaban a rendir las cepas plantadas prudentemente en los siglos coloniales y que andando el tiempo iban a imponer una robusta vocación vitivinícola. En la época que nos interesa (fines del siglo xvir) el sobrante de la modesta producción vitícola de Mendoza se canalizaba ya hacia los mercados urbanos de Córdoba, Tucumán y Buenos Aires, de modo que obviamente el abastecimiento del sector indígena pobre y marginado quedaba a expensas del avisado productor chileno.

Los ejemplos concretos de tropas consagradas al transporte y mercadeo de vinos abundan en los documentos revisados. Uno de los más típicos y con precisiones geográficas es revelado en 1791 por el Comandante del Fuerte de San Carlos, cuando informa a su superior en Mendoza Que acaban de regresarse del Rio Grande y Campanario unos chilenos que habian entrado de Maule con veinte $y$ tantas cargas de vino a tratar ponchos y que iban con el dnimo de volver con lo mismo, agregando en otra parte que: en los Toldos de Ancán se esperaba por horas nada menos que al Capitán de Amigos de la Villa de San Fernando con sesenta cargas de vino. Se explica entonces que las diferentes prohibiciones tengan el sentido específico de impedir dicho tráfico.

Con todo, no sólo existe la modesta corriente comercial desde Chile, porque hay que consignar también una reciprocidad desde el lado argentino. Los indios pehuenches tienen a su vez necesidades que satisfacer y especies o producciones que ofrecer; lo que cambian en trueque o compran en la región mediterránea es el trigo de que se alimentan y lo que venden naturalmente es aquello que el medio les proporciona en abundancia o lo que fabrican en su pobre industriosidad. Según la opinión autorizada de un informante oficial en 1799, el comercio de los indios por los boquetes ubicados entre Maule y San Fernando se reducía todos los años:

"a treinta o cuarenta ponchos que traen con algunas mulas y algún poco de sal todo lo cual cambian por trigo y alcanzan a juntar treinta o cuarenta cargas que son con las que se vuelven a sus tierras. Este corto acopio que ellos hacen es en Ia primera salida que verifican en fines de diciembre y traen consigo todo lo que han podido adquirir y trabajar en los ocho o nueve meses que les impide la cordillera, porque desde el mes de abril ya suspenden el pasarla" (8).

En algunas oportunidades el indígena que viene a comerciar a este lado viene premunido de licencia e incluso pide protección oficial a las autoridades

(8) Archivos de la Capitanía General. Vol. 507. 
chilenas, así lo deja ver una comunicación del Subdelegado de Cauquenes en enero de 1794 que reza como sigue:

"Estando en la isla de Maule salió por el boquete del río de Achigueno un indio pehuenche de los que habitan en la parte del oriente de las cordilleras en las cabezeras del Maule, este me vino aver manifestándome pasaporte y carta de amparo librada por 'Don José de Amigorena, Comandante de las Milicias y Fronteras de la Jurisdicción de Mendoza y en su virtud me pidió permiso para salir por el citado paso a este partido con su comercio de sal, ponchos, plumajes y que para practicarlo con seguridad le nombrase al capitán Don José Barros, su amigo, para que le patrocinase, escoltase y defendiese de los malos españoles y que le fuese a sacar de su tierra y acompañar en los caminos como que es hombre de bien y de respeto" (9).

Una nota posterior pone de manifiesto que en la ocasión mencionada entró un gran número de indfgenas bajo el seguro solicitado sólo por uno y para uno, instruyéndose en consecuencia al Capitán Barros para que lograse de los indios el compromiso de realizar una salida en cada verano y nada más que por el boquete del Achibueno, lógicamente esta medida era válida sólo para la región situada al Sur del Maule.

\section{TraficANTES $\mathrm{x}$ DERROTEROS.}

Los protagonistas del tráfico desde el lado occidental de la Cordillera son chilenos y españoles nombrados más o menos indistintamente en la documentación que fundamenta este trabajo. Los chilenos en su mayoría son simples particulares; los españoles por lo general son militares, pero repetidamente los primeros aparecen coludidos con los últimos en el mismo negocio ilegal. Al parecer los chilenos dedicados a esta actividad eran personas modestas y de poco valimiento, lo prueba el hecho de que fueran capaces de convivir con los indígenas en sus tolderías por períodos más o menos largos y sin mayor esfuerzo. En la lista de los que pasan a la vertiente oriental figuran, por lo demás, muy pocos dones, distinción reservada para los escasos militares españoles que consienten o hacen destacadamente el comercio como ya se ha insinuado.

Los traficantes provienen de lugares situados en el Valle Central o en la Cordillera de la Costa del Sur mediterráneo chileno, es decir, de lugares que están dentro de la jurisdicción de los partidos de Colchagua, Curicó, Talca, Maule y Linares. Ilustrativa acerca de la procedencia de los arrieros y comerciantes es una averiguación hecha por un Capitán de Amigos en 1794 sobre los que se estaban aprontando para la entrada a la tierra por el paso de Maule; en

(9) Id. Vol. 507. 
tre ellos se individualiza a un tal Burgos que vive en la Isla; a un tal Portales que es un viejo costino que vive por Namen o por la Huerta; a un Alarcón que viene de Ancoa; a un Juan Cerda que viene de Basaes; a un tal José Vásquez que viene de la 'Vega de Salas y a otro que parte desde Llepo, lugares que se emplazan en la Cordillera costera al Sur del Maule o que se suceden en el Valle Central siguiendo el curso del Achibueno en la proximidad de Linares (ver mapa No 1). Es sintomático, en relación con lo que llevamos dicho, que los parajes aludidos se encuentren en una región donde la trashumancia y la viña tienen una añosa tradición. La nómina que se viene de indicar es la única noticia detallada que aparece en los documentos respecto de los puntos donde se origina el tráfico o donde los dueños de las tropas reclutan a sus peones; la información permite localizar los lugares más secundarios que señalan la procedencia de los comerciantes del sector Maule-Linares, pero ella, con todo, no pasa de ser un ejemplo muy particular. En realidad, otros documentos aluden incidentalmente y sin pormenores a algunos troperos que son oriundos de las ciudades del Valle Central, concretamente de Talca, Curicó y San Fernando.

Ahora bien, si complementamos estos datos que en ningún momento hemos querido citar como mera curiosidad, con los relativos a los derroteros seguidos por los traficantes, se puede llegar a tener una idea bastante clara del área más directamente influenciada por la corriente comercial de ultracordillera. En este aspecto podemos afirmar con buena base que los pasos frecuentemente utilizados por el tráfico son: en Colchagua, los boquetes de "Cauquenes y Talcaregua" (¿frente a estos parajes?), en la misma región es frecuentado el boquete de "Gustamante", donde se juntan dos caminos por los cuales suelen transitar a menudo los indios, el uno llaman el de las Damas y el otro de Los Maitenes (10); en Curicó, el boquete que está en la "desembocadura" del río Teno y el del Planchón; más al Sur, el de la "desembocadura" del Maule, el del Portillo y el boquete del río Achibueno. Por último, frente a Chillán se frecuentaba el paso de las fuentes del Nuble (San Fabián de Alico). El boquete que canalizaba el movimiento más importante era el del Planchón, tanto porque en las nacientes del Teno vivia una reducción numerosa de Pehuenches, como porque dicho paso estaba a cargo del Capitán Nicolás Vergara, célebre por sus connivencias comerciales con los indios cuyo tránsito, por extraña ironía, tenía el deber de vigilar. Lo propio ocurre en el boquete del Maule, donde también habitaba un agrupamiento Pehuenche de cierta magnitud.

En la parte más septentrional de la región, frente a Rancagua, se usaba eventualmente un derrotero cuya descripción minuciosa hemos encontrado en los Archivos, según el documento esta otra ruta se iniciaba saliendo de esia Villa de Triana al paraje que dicen de Machali y se continuaba por el paraje de los Maitenes hasta el nacimiento del río Blanco, desde donde partían dos

(10) Archivos de la Capitanía General. Vol. 534. Reconocimiento para la fortificación de los pasos cordilleranos, efectuado por el Ingeniero Lorenzo Arrau en enero de $\mathbf{1 7 7 0 .}$ 
caminos, uno que seguía siempre al Este hasta alcanzar el Portezuelo de San Antonio y otro que por el Norte iba a caer al Valle del Jaurua (1l).

Finalmente en el extremo meridional de la región mediterránea, el derrotero del paso del Antuco servía a las comunicaciones del litoral Penco-Concepción en un plano de importancia que tendremos ocasión de precisar más adelante.

\section{Significación del tráfico por el Sur del Chile Mediterráneo}

Salvo la esforzada y heroica voluntad de trasmontar Los Andes a toda costa, nada de semejante hay entre el activo, controlado y honorable tráfico por el Norte y la modesta migración o las ilegales entradas que tienen lugar por el Sur de la región mediterránea chilena. En el Norte el comercio se práctica abiertamente y constituye una corriente económica de bastante envergadura; el tráfico se encauza allí por uno o dos derroteros que se habilitan y atienden con el interés que tienen en tal cosa, las ciudades que conectan, las economías que movilizan, los hombres que por ellos viajan e incluso las ideas que por ellos pudieran entrar. En el Sur mediterráneo, el tráfico es oculto o está lleno de subterfugios; utiliza los derroteros más diversos por difícultosos que ellos sean y aunque su importancia económica es mínima, su razón de ser es el lucro individual, esta finalidad es tan ostensible que aparentemente no deja Iugar a los demás contactos propiamente civilizadores.

En suma, el comercio por el Sur es verosímilmente irrisorio por su monto, un informante oficial en 1799 lo califica de corto y ridiculo, pero además es un comercio sin prestigio, marcado por la mala fama. Las autoridades lo proscriben formalmente, aunque en la práctica lo consienten por el tacto que hay que observar con los indios. Los traficantes no tienen la simpatía, ni la confianza de los altos funcionarios y a menudo son descritos de la peor manera; tampoco es raro que se les considere poco menos que un peligro público o que se les asigne alguna intención política como se deduce de una comunicación del propio Ambrosio O'Higgins en 1794:

"Los españoles que toman aquel destino (morar y conchabar con indios de la otra banda) y hacen este tráfico, son ordinariamente facinerosos, pérfidos y malévolos que huyendo aquí de la justicia van a inspirar de pronto entre los indios ideas diabólicas contra el gobierno y a la vuelta roban a los mismos indios y les hacen otras mil iniquidades porque estos confirman su aversión al nombre español" (12).

(11) Id. Vol. 534. Reconocimiento del derrotero del camino trănsito para el otro lado de Ia Cordillera de Los Andes por el paso que llaman de los Maitenes en la jurisdicción de Rancagua, efectuado por el Tnte. Norberto Mancilla.

(12) Archivos de la Capitania General. Vol. 507. 
Por curiosa contrapartida estos hombres así caricaturizados tienen las resolución y la pertinacia suficiente para vencer la Cordillera grande todos los veranos con una continuidad que nos parece constituye una caracterfstica importante del tráfico por el Sur. Ella justamente nos hace creer en una constancia de las relaciones con Cuyo que va más allá del menguado período comprendido en los documentos analizados. Ahora bien, dentro del mismo lapso estudiado, por 1o menos en cuatro oportunidades los Gobernadores prohiben dicho tráfico (I786-1791-1792-1794) y sin embargo, documentos posteriores terminan por reconocer que a pesar de haberse: prohibido estrechamente la entrada de espanoles con venta por los boquetes de la cordillera, no ha cesado este abuso y libertad tan perniciosa, damdo continuos motivos de queja a las reducciones de Mendoza. En nuestra opinión estas órdenes frustradas reflejan no sólo la actitud condescendiente en los hechos de la autoridad española con los indios, a quienes no siempre descomplacía la mencionada forma de comercio, sino también la fuerza de una práctica prolongadamente establecida.

Posiblemente los agentes anónimos de este tráfico fueron realmente delincuentes, pero aun en este caso nosotros quisiéramos que se nos permitiera aqui rendir un homenaje a su nombre, no porque seamos partidarios de la delincuencia de ninguna época, sino por el inmenso favor que con sus azarosos viajes hicieron a la geografía de la vinculación con la Provincia de Cuyo. En ellos reconocemos a los pioneros y sustentadores de una comunicación que ha comienzo del siglo xix proyectó volcarse regularmente por el Paso del Antuco (13) y que hoy en día recién encuentra un cauce moderno e insospechadamente promisorio a través del Paso del Pehuenche (14). Una vez más el pasado responde del porvenir.

(13) La idea de unir mediante un camino la región periférica Norte de la Frontera Araucana con las provincias transandinas reconoce lejanos precedentes. Concebida en tiempos del Gobernador Ambrosio O'Higgins, fue objeto de intentos serios por materializarla bajo el Gobiemo de Muñoz de Guzmán. En afecto, entre 1804 y 1806 por lo menos cuatro reconocimientos se hicieron con este fin por distintos boquetes cordilleranos. (Expediciones del Cap. José Barros a los boquetes de Ancoa, Achibueno y Alico; del Cap. José Santiago Cerro y Zamudio que llegó a Buenos Aires explorando los boquetes del Norte del Maule; de Justo Molina que por el boquete de Alico llegó en 1804 al valle del Atuel y luego a Mendoza y Buenos Aires, para regresar en el verano de 1805 por el boquete del Antuco; de don Luis de la Cruz, alcalde de Concepción, que en el verano de 1806 y también por el paso del Antuco llegó hasta Córdoba y Buenos Aires). La última expedición fue la más interesante por las observaciones sobre el paisaje y sobre Ja vida de los Pehuenches, siendo además la tentativa más seria para construir un camino carretero por dicho paso, cuyo presupuesto fue presentado por el jefe de la expedición a su regreso. Finalmente el camino no se construyó por falta de incentivos económicos reales entre dos regiones que a ambos lados de la Cordillera presentaban caracteristicas fronterizas. (Concepción, San Rafael y Sur mendocino).

(14) La ruta internacional por el Paso del Pehuenche fue inaugurada solemnemente el sábado 8 de abril de 1961, concretándose asi la vieja aspitación de unir el Sur mediterráneo chileno y la región de Cuyo. 


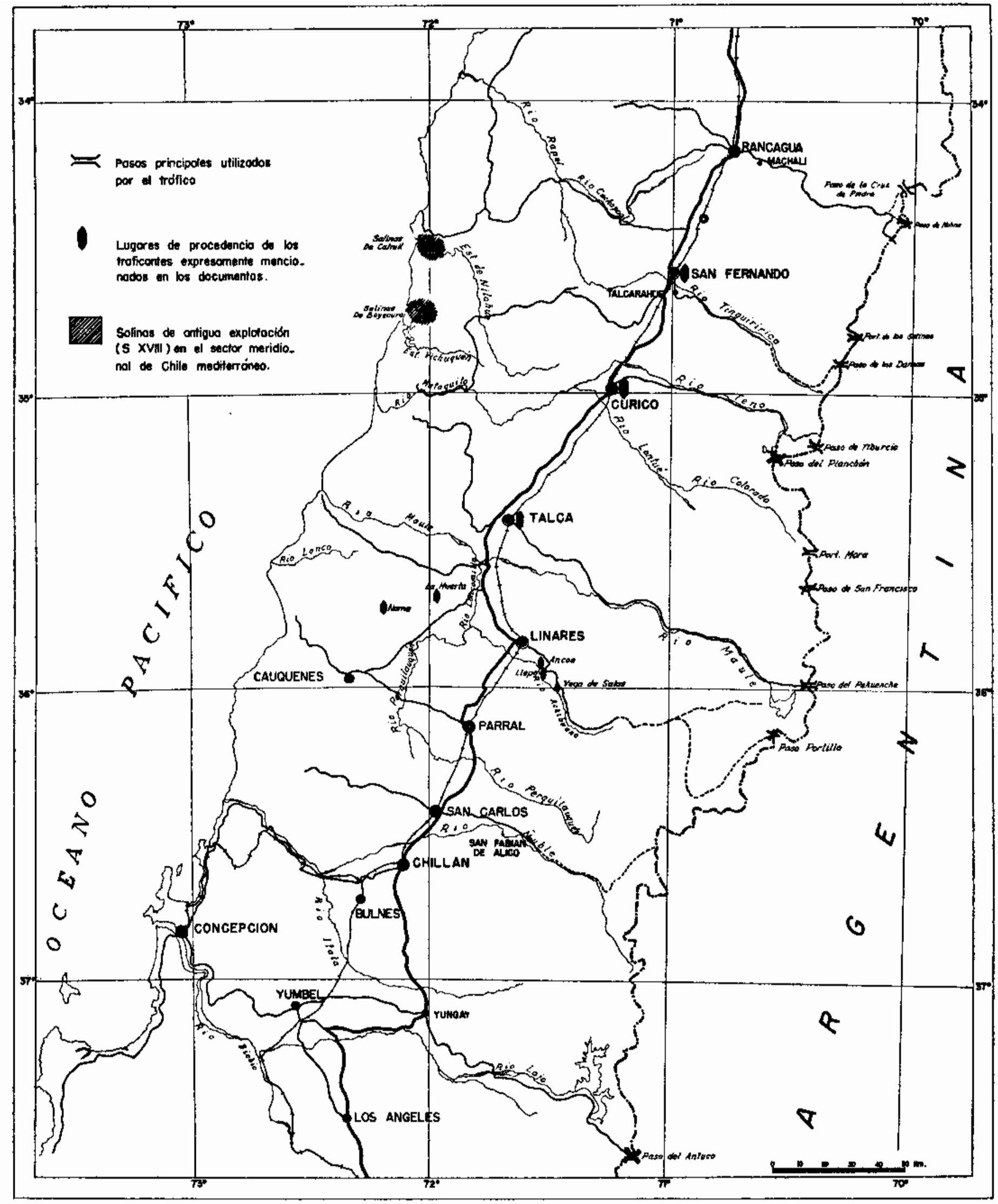

Mapa No 1.-Sección meridional de Chile Mcditerráneo con los principales derroteros del tráfico con Cuyo a fines del siglo xvir 


\author{
II. (Informe solicitado por el Fiscal a Dn. Vicente de la Cruz, Regidor \\ Decano de la Ciudad de Talca, sobre la prohibición de introducir \\ engordas de animales y a su sombra comercio de licores a tierras de \\ indios, establecida en un bando del Subdelegado de Curicó).
}

\title{
M.I.S.P.
}

Dn. Vicente de la Cruz obedeciendo al Supr, Decto, de V.E. que antesede sobre el informe to que me parczca más conveniente del contcsto del vando del subdelegado de Curicó y sobre todos y cada uno de los puntos de la carta de 7 de Julio de 96 de la superioridad. Informo que gralmente sea proivido en todos estos partidos la introducción de licores, cavallos y todo comercio a los Indios Pehuenches, para ello se han repetido varios vandos declarando a los trasgresores varias penas aflictivas y pecuniarias, aún no se ha conseguido el intento de cortar este corto comercio antes por el contrario prudentemente juzgo ocasionado algunos alvorotos entre los mismos Indios. El caso es que los que obedecen los vandos y observan las leyes y presec. tos son los hombres de vien, los que se aabstiencn en sus deveres, pero los fasinerosos vahamundos no hasen caso de la justicia ni temen sus amenazas porque ven lo dificil que es encontrarlos en el delito. Esta laya de gente es la que regulatmente introduce a la tierra licores y cavallos que rovan en estos lados para venderselos a los Indios que no solo contentos con lo que rovan acá sino que les rovan a ellos, los engañan, les faltan a la fe de los tratos y últimamente desacreditan el nombre español cometiendo toda laya de vicios y crimenes. Me parece que si se tomara opuesto sistema, mejores progresos se arían con el trato de los Indios consediendo gralmente que todo el que quisiese introducir ganados, frutos, licores y demas especies (esepto armas) tuviesen livertad de ascrlo y pudiesen camviar estas especies con los Indios en las de ellos que se redusen a ponchos, alguna sal y cavallos y mulas que crian. Que se les presise a los que uviesen de dentrar Jeven licencia por escrito y la presenten al cacique a quien se le podrá prevenir que cualesquiera Español que introdujiese efectos sin el requisito de llevarla le decomisasen cuanto condugesen y si posible les fuese los remitiesen reo a la jurisdicción que corresponda para aplicarle las penas que se tuviesen a vien destinarle supucsto que los indios no saven leer y que cualesquiera los podrá engañar llevandoles papel falso se les podrá prevenir que todos los papeles los guarden, que observen y tetengan en la memoria los sugetos que los an llevado para que a las salidas que estos acostumbran tener cada aũo a estos partidos, los muestren al sugeto que se señalasc para que de estos papeles o licencias a quien se le podrá asignar ocho reales por cada guía que diere con el reato que aia desacar en el paso de dentrada que le corresponda interesándoles en parte de la multa que se les aplicase a los contraventores para que instimulados de este interés se empeñen en solicitarlo. Los sugetos más a propósito para que den las guías me parese serán los capitanes de amigos que ay en los partidos por el conocimiento que tienen de Jos caciques y demás Indios. Entablado estc comercio libre, los Indios serán avastecidos de lo poco que necesitan por los espafioles dueños de las especies que venden, se conseguirá que españoles e indios tengan amistades y correspondencias recíprocas y en vreve tiempo esos pocos Indios se españolizaran, no solamente con el uso de la lengua sino también de las costumbres y muchos de ellos se aran cristianos pues es un dolor que cuatro indios en el sentro de tantos españoles se mantengan gentiles.

Según estoy informado todos los indios Pehuenches que estan situados de frente del río Teno para el lado de Mendoza no pasan de tresientos indios de lanza y los manda como cacique Gvor. Pichicolimilla. Otra reducción que esta enfrente del río de Maule que en estos años antecedentes vivió en el lugar nombrado las Barrancas governada por el cacique Guilcapi y oy resiđe en las vegas de Guilquibilo serca del rio Maule y actual la grna, el cacique Chañavilo conpondrá solo poco mas de treinta Indios de lanza. Donde reside algún cuerpo regular de Indios es desde enfrente del tio Nuble para la frontera que su casique gvor es Caullamante. Tienen estos su correspondencia y conecciones con el Sr. Govr. Intendente de Concepción y el 
Comdte. de la Plaza de los Angeles: Las dos partidas anteriormente nombradas mandadas por Pichicolimilla y por Chañabilo son las que trafican los Partidos de Maule y Curicó y San Fernando según y como les agrada para los yerbajes de sus animales.

Sobre los puntos de la carta de esa Superioridad de 7 de Julio de 96 informo a V.E. no aver tenido noticias que los subdelegados aian sido autorizados por esa superioridad pata permitir licencia deste tráfico antes por el contrario orden para que le impidiesen y como a sido el comercio que asta aqui sea echo clandestino jamas sea tratado del metodo y orden con que avian de dar cuenta los traficantes de las novedades de su viaje ni menos averles intimado dros de contribuciones reales, municipales o personales, ni creo se pueda entablar alguna por lo corto y ridiculo deste comercio, hablo desde Maule asta Sn. Fernando, pués las salidas que han hecho los Indios por los boquetes deste partido en los diez años que fui Subdelegado se an redusido a treinta o cuarenta ponchos que traen con algunas mulas y algún poco de sal todo lo cual camvian por trigo y alcanzan a juntar treinta o cuarenta cargas que son con las que se vuelven a sus tierras. Este corto acopio que ellos asen es en la primera salida que verifican en fines de Diciembre y traen consigo todo lo que han podido adquirir y travajar en los ocho o nueve meses que les impide la cordillera por que desde el mes de Abril ya suspenden el pasarla. Por aquí se puede inferir qual sea la pobreza de los Indios pues en tantos meses no alcanzan a tener fuerzas para acopiar mas que treinta o cuarenta cargas siendo el grano que mas apetecen y del que enteramente necesitan por que en sus lugares no lo cultivan. Entre los meses de verano, de Dvre. a Abril salen continuamente a cambiar este grano, pero es en mucho menos cantidad que la que acopian en Dvre. Este corto comercio lo an echo estos años pasados quando la rélucción que vivia en el Jugar de las varrancas gvda. por el cacique Guilcapi era más número y casi tenía la mitad del cuerpo de Indios que se allan asia este frente hasta Sn. Fernando que con las guerras que unos y otros han tenido en la que fue mueto Guilcapi quedó la reducción de este arruinada constando oy sólo de poco más de treinta indios de lanza.

En consideración de lo que a V.E. expongo sta alta penetración conoserá a fondo si sera tolveniente consentir el comercio libre a los españoles con las precausiones que sito harriva, 0 enteramente impedirlo y por consiguiente si convendrá en caso de permiso consederlo livre sin pención alguna por su cortedad o ponerles las que se estimen justas siendo to que en la materia puedo informar a V.E. Sn. Agustín de Talca y Sepvre. 7, 1799.

M. I. S. P.

Vicente de la Cruz.

(Archivos de la Capitania General, Vol. 507). 